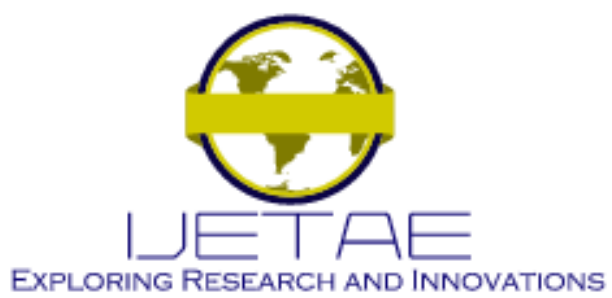

International Journal of Emerging Technology and Advanced Engineering

Website: www.ijetae.com (E-ISSN 2250-2459, Scopus Indexed, ISO 9001:2008 Certified Journal, Volume 11, Issue 12, December 2021)

\title{
Proposal for a Social Distancing Breach Identification Device to Prevent the Spread of COVID-19
}

\author{
Rosa Perez-Siguas ${ }^{1}$, Eduardo Matta-Solis ${ }^{2}$, Hernan Matta-Solis ${ }^{3}$ \\ ${ }^{1,2,3}$ Universidad María Auxiliadora \& Av. Canto Bello 431, San Juan de Lurigancho
}

\begin{abstract}
This research is based on the problem of the spread of COVID -19, so it is necessary to maintain social distancing to avoid its spread in the population, the Bluetooth sensor of the cell phone will be used to detect a contact, which will alert the person who You must keep your distance and record it, after this you can analyze the information collected from the contacts for decision-making in order to minimize the spread of COVID-19. The Scrum methodology was used to develop this system, modern technologies are also used in software development. As a final result, a prototype of the proposed objective has been made, which aims to be able to carry it out for development and put it into production.
\end{abstract}

Keywords-- Android Studio, Bluetooth, Social distancing, Scrum methodology.

\section{INTRODUCTION}

Currently on this date we are in a pandemic, due to the coronavirus (COVID-19) it is a disease that can be transmitted through the air and the potential for its spread is very high, through the relevant public health authorities at the national level and local. Cases have been reported in many countries around the world, and outbreaks have occurred in several of them. The Chinese authorities and those of other countries have managed to slow down the advance of the outbreaks, but the situation is unpredictable and is to regularly check the latest news. There are several precautions that can be taken to reduce the probability of contracting or spreading COVID-19 [1], for which measures are being taken to protect health, one of the most important is to maintain social distancing [2], about 2 meters between people using the Bluetooth Low Energy (BLE) function to use its proximity sensors to detect nearby devices.

Therefore, an application was designed with the ability to notify users if they are having another person nearby and to geolocate crowds. In addition to being able to apply the same application for possible next pandemics that require maintaining social distancing [3].
With this application you can have a record of contact between people, in addition to alerting people who must keep their distance, so you can also have a report indicating the geographic location where these agglomerations occur.

\section{Methodology}

\section{A. Scrum}

Scrum is a methodology that has a group-oriented approach, organizes, plans and develops complex projects, for example, web and mobile systems through a collaborative functional environment and adaptable to change, based on prioritizing and delivering value to the final product.

Scrum es un enfoque de mejora iterativo e incremental que prioriza la flexibilidad y adaptabilidad en entornos complejos y cambiantes. Scrum es una metodología que consta de varios pasos a seguir y garantizar productos de calidad, a tiempo y dentro del presupuesto. Además, Scrum es un framework enfocado a la organización y gestión que proporciona una base sobre la cual las organizaciones pueden agregar una implementación única de acuerdo a sus enfoques y necesidades, tiene ventajas como la selección flexible, basada en la priorización de requisitos para el desarrollo. Sprint [4].

a) Analisys of requirements: SCRUM is based on the incremental delivery of requirements, considering the prioritization of user stories depending on the value assigned by the client. Likewise, this agile methodology is applicable when empirical project control is required [5]. Therefore, the requirements for the development of the application were chosen through research and reliable sources from the Ministry of Health, as found in Table 1 of the requirements analysis. 


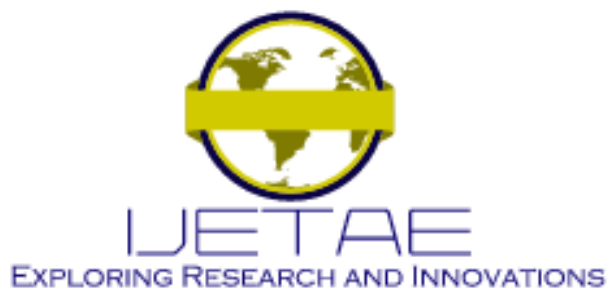

International Journal of Emerging Technology and Advanced Engineering

Website: www.ijetae.com (E-ISSN 2250-2459, Scopus Indexed, ISO 9001:2008 Certified Journal, Volume 11, Issue 12, December 2021)

TABLE 1

Requirements Analysis

\begin{tabular}{|l|l|}
\hline item & \multicolumn{1}{|c|}{ Description de requerimientos } \\
\hline 1 & $\begin{array}{l}\text { A mobile application that detects contact with } \\
\text { another user. }\end{array}$ \\
\hline 2 & $\begin{array}{l}\text { Register the contact with another user. } \\
\text { Geolocate the contact }\end{array}$ \\
\hline 4 & $\begin{array}{l}\text { Have a report of the contacts that each user had. } \\
\text { Have a heat map to identify which areas are more } \\
\text { crowded. }\end{array}$ \\
\hline 5 & Have a web application to view the reports \\
\hline 6
\end{tabular}

b)Sprint development: A Sprint is a cycle or an iteration that you have in projects with a duration of two to four weeks. The objective of each Sprint is to achieve a value delivery of the product. Likewise, in the first Sprint it will contain the minimum viable version of the product as the elementary functionalities, also considering the prioritization of the client [4]. Therefore, for the planning of the development of the mobile application it was divided into three Sprint as shown in Table 2 Sprint development.

TABLE 2

SPRINT DEVELOPMENT

\begin{tabular}{|l|l|}
\hline \multicolumn{1}{|c|}{ item } & \multicolumn{1}{c|}{ Description } \\
\hline \multirow{3}{*}{$\begin{array}{l}\text { Sprint } 1 \\
\text { N }\end{array}$} & $\begin{array}{l}\text { R1 A mobile application that detects contact } \\
\text { with another user. }\end{array}$ \\
\cline { 2 - 2 } $\begin{array}{l}\text { S2: Register the contact and the location that } \\
\text { there was with another user. }\end{array}$ & R6: Have a web application to view the reports. \\
\cline { 2 - 2 } 2 & R3: Geolocate the contact \\
\hline \multirow{2}{*}{\begin{tabular}{l} 
Sprint 3 \\
\cline { 2 - 2 }
\end{tabular}} & $\begin{array}{l}\text { R5: Have a graphical report on the contacts. } \\
\text { Have a heat map to identify which areas are } \\
\text { more crowded. }\end{array}$ \\
\hline
\end{tabular}

\section{B. Technological tools}

Diagrams.net: Is a free online cross-platform, open source graphics drawing software developed in HTML5 and JavaScript. Its interface can be used to create flowcharts, mockups, wireframes, UML diagrams, organization charts, and network diagrams [6].

Android Studio: It is a development environment, a software that has tools and services so that developers can create applications for Android [7]. The use of this technology is essential to carry out the development of the mobile application
NodeJS: Is a cross-platform runtime environment for the server layer (on the server side) based on JavaScript [8]. The use of this software is to carry out the development of the web application, using express for the development of the business logic and the templates for the visual part of the web system.

\section{Bluetooth Low Energy (BLE):}

Bluetooth low consumption (BLE) is a technology used to discover devices and check for services, its most typical uses are: transferring information with other devices and interacting with proximity sensors. This technology will be used to develop the functionality to detect contact with another user [9].

Fig. 1 shows in which scenarios a contact with another user is considered and when this happens the contact is registered in the database, to make inquiries, make reports or analyze the data.

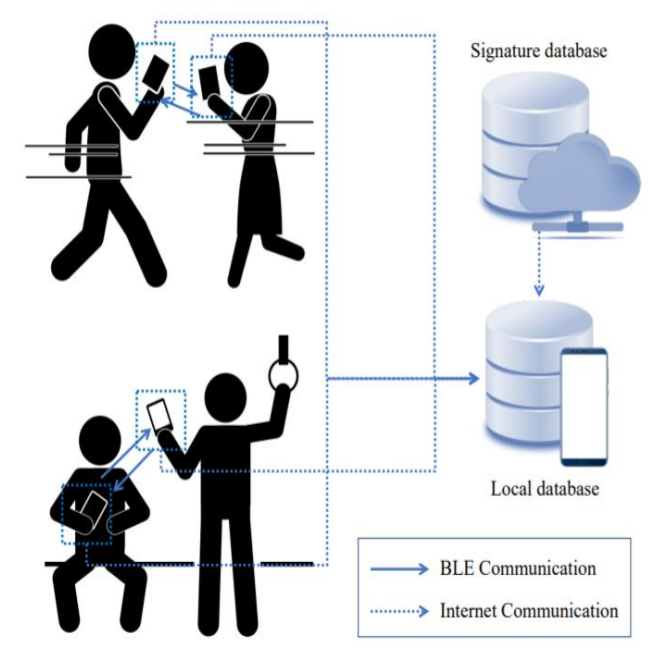

Fig 1. Contact registration scenario using BLE.

A smart contact tracing system is proposed that uses smartphone BLE signals and machine learning classifiers to automatically detect such potential contacts with infected people [9].

Each smartphone calculates its distance from other users' phones and issues alerts in real time when social distancing rules are not met.

The need for distance measurement and tracking technology has further increased in importance following the spread of COVID-19. With businesses around the world planning their controlled reopening, solutions are being sought to help ensure safe distances between employees and improve contact tracing. 


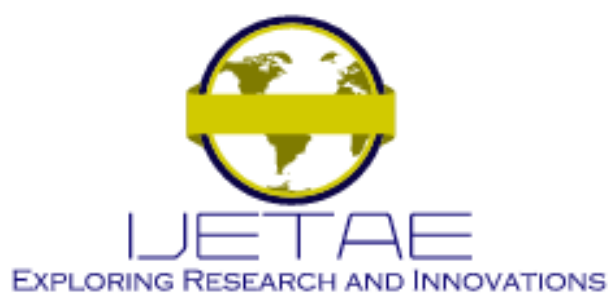

International Journal of Emerging Technology and Advanced Engineering

Website: www.ijetae.com (E-ISSN 2250-2459, Scopus Indexed, ISO 9001:2008 Certified Journal, Volume 11, Issue 12, December 2021)

Currently we have BLE solutions for distance and positioning measurements based on the measurement of the strength of the received radio signal, known as the received signal intensity indicator (RSSI). However, these measurements can have intermediate noise due to the sensitivity of objects that interfere with the radio, blocking or altering the signals [10].

Currently the SDK takes advantage of an implementation such as that of a radar to be able to improve the distance measurement between the connected BLE devices. By exchanging Bluetooth data packets with constant frequency changes, the $2.4 \mathrm{GHz}$ radio generates the necessary signals for a phase-based range [10].

\section{RESULTS}

\section{A. Application prototypes:}

The development of the prototypes is based on the identification of the business needs of the end user, the development of a mobile application was carried out through a system design that aims to ensure that the application meets the functional specifications in the form of structured interface designs. The prototype has been modeled and tested, through an analysis of system requirements in order to identify the business needs, being for the user a good reference on the deliverables of each sprint.

The prototypes were used to get a clear idea of what the final product will look like taking into account the requirements of the project. Likewise, the interested parties can clarify their expectations of the final product, it is also important for the developer an overview of how the structure of the final application will be, giving a vision of how each requirement is structured. The prototype will be developed in Diagrams.net, and will contain a visual sample about the structure of the application.

In the development of the prototypes of the application, it was based on the prioritization of the requirements and the basic functionalities for the operation of the application in order to increase the value of the business, based on the above, this was divided project in 3 Sprint.

1) Sprint 1: The requirements were developed: R1, it was possible to design a mobile application with the ability to detect another user using the BLE technology where its proximity sensors are used, to subsequently register the contacts, also the CPS codes of the android device In a database Fig. 2, this application will be running in the background so that it works at all times, also when a contact is detected an alert will be issued to the mobile device as seen in Fig. 3.

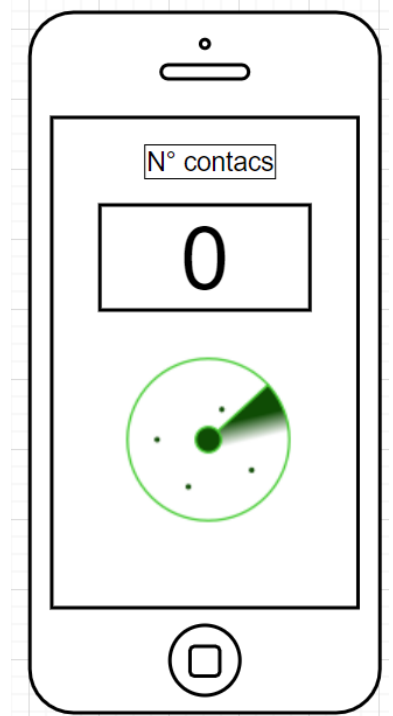

Fig. 2. Aplicación móvil registro de contactos

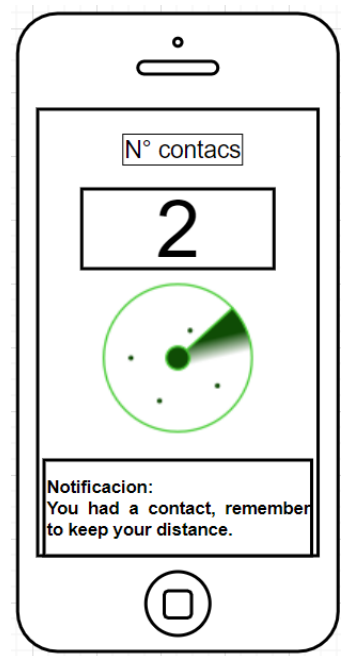

Fig. 3. Application showing notification when contacts are detected

2) Sprint 2: The requirements were developed: R4 and R5, it was possible to design a web application with the ability to carry out searches for contacts with other users, having as parameters the user name and also the start and end date of the search, in addition, it will be possible see the points of the geographical location of the contact carried out thanks to the GPS record and also using the Google maps API for the use of the map in this application as seen in Fig. 4. 


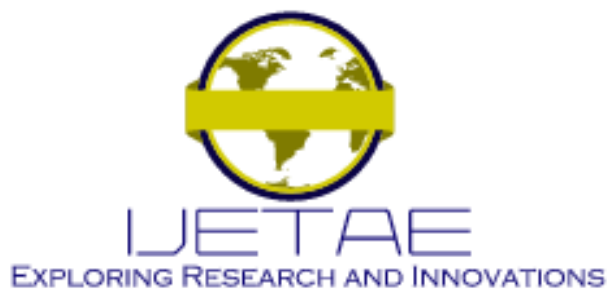

International Journal of Emerging Technology and Advanced Engineering

Website: www.ijetae.com (E-ISSN 2250-2459, Scopus Indexed, ISO 9001:2008 Certified Journal, Volume 11, Issue 12, December 2021)

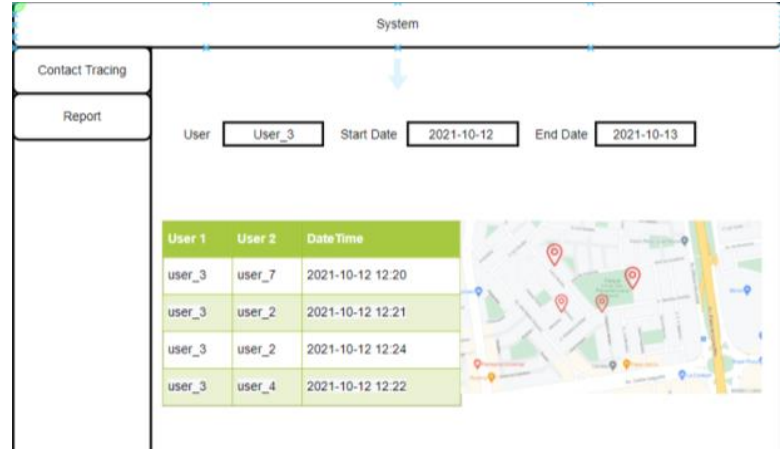

Fig 4. Contact tracking view.

3) Sprint 3: The requirements were developed: R3 and R6, it was possible to design a web application with the ability to show a graph that shows the behavior of users through the days, with this it will be possible to know if social distancing is respected, analyze the information and take actions, likewise the Google Maps API was also used to obtain the heat points to know geographically where more agglomerations occur, which will be obtained from the GPS coordinates emitted by mobile applications. With this feature with respect to Fig. 5 you can keep track of the crowds that occur and then be able to make decisions about what security measures to take.

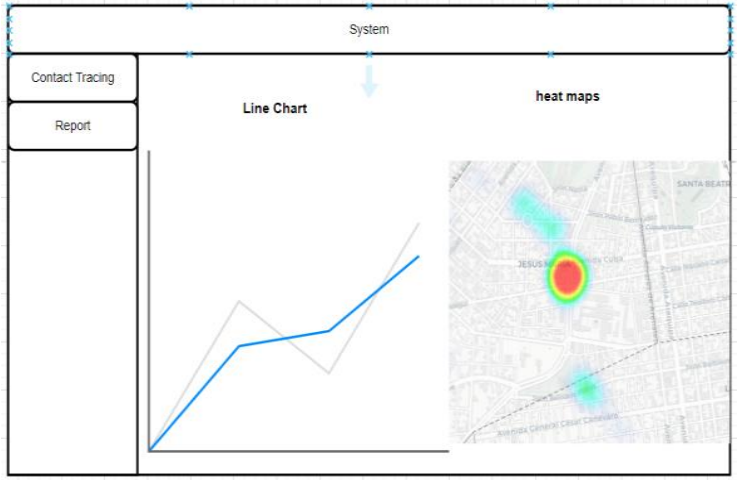

Fig 5. report view dashboard.

\section{DISCUSSION}

Regarding the Scrum methodology, unlike traditional methodologies, Scrum is focused on short-term deliverables giving continuous improvements to the client, thus also giving a retrospective if it was what the client needed or what can be improved for the next deliverable, in addition to the I echo that the needs can change over time compared to the traditional methodology, that the entire project is delivered at the end, when everything is already built, for which the methodology is willing to change compared to the traditional methodology.
As for the technologies, diagrams.net compared to other design tools, this is worked online because it is not necessary to install it on our computer, in addition to that the works can be saved in the Google Drive making the work more efficient, and on The BLE is a technology that is based on bluetooth, compared to other strategies such as only by GPS to detect if there are 2 or more individuals nearby, the margin of error is much greater compared to BLE, that is why this technology is used more, in cases that require the use of their radar, and regarding other projects, the use of GPS is used here to be able to know the geographical point to be able to know where the contact occurred and with that information have reports interesting with is shown in this investigation, such as for example heat map.

Finally, the use of this application will be able to have control over which users are having contact with others, and if in the case it is known that a user has COVID-19, it can be known with whom other people had contact and the responsible authorities can carry out the corresponding actions and with the heat map you can control the places where more agglomerations occur.

\section{CONCLUSIONS}

The prototype of this application was developed, to be able to detect contacts between people in order to maintain social distancing.

The information that is collected from the contacts will be used to obtain reports to control social distancing, with this information actions can be taken if there are cases of high agglomeration.

For future research, artificial intelligence could be used to make prediction cases about possible places of high crowding, thus being able to anticipate decision-making in order to avoid more contacts between people.

This research can be used for future pandemics, if necessary to control social distancing, thus preventing the spread of the virus.

\section{REFERENCES}

[1] Ramón, M., Abreu, P., Jesús Gómez Tejeda, J., Alejandro, R., \& Guach, D. (n.d.). Revista Habanera de Ciencias Médicas Clinicalepidemiological characteristics of COVID-19. http://www.revhabanera.sld.cu/index.php/rhab/article/view/3254/ 2505

[2] Zanin, M., \& Papo, D. (2020). Assessing functional propagation patterns in COVID-19. Chaos, Solitons and Fractals, 138 https://doi.org/10.1016/j.chaos.2020.109993

[3] Ramón, M., Abreu, P., Jesús Gómez Tejeda, J., Alejandro, R., \& Guach, D. (n.d.). Revista Habanera de Ciencias Médicas Clinicalepidemiological characteristics of COVID-19. http://www.revhabanera.sld.cu/index.php/rhab/article/view/3254/ 2505 


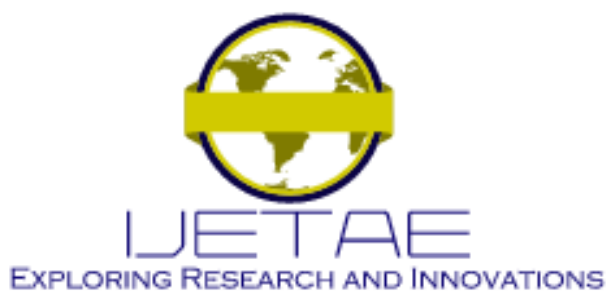

\section{International Journal of Emerging Technology and Advanced Engineering}

Website: www.ijetae.com (E-ISSN 2250-2459, Scopus Indexed, ISO 9001:2008 Certified Journal, Volume 11, Issue 12, December 2021)

[4] S. Ashraf and S. Aftab, "Pragmatic Evaluation of IScrum and amp; Scrum,” Int. J. Mod. Educ. Comput. Sci., vol. 10, no. 1, pp. 24-35, Jan. 2018, doi: 10.5815/ijmecs.2018.01.03.

[5] A. Srivastava, S. Bhardwaj, and S. Saraswat, "SCRUM model for agile methodology," in 2017 International Conference on Computing, Communication and Automation (ICCCA), May 2017, pp. 864-869, doi: 10.1109/CCAA.2017.8229928.

[6] Jaimez-González, C. R., \& Martínez-Samora, J. (2020). DiagrammER: A Web Application to Support the TeachingLearning Process of Database Courses Through the Creation of E-R Diagrams. International Journal of Emerging Technologies in Learning, 15(19), 4-21. https://doi.org/10.3991/ijet.v15i19.14745.

[7] Esmaeel, H., \& Esmaeel, H. R. (2015). Apply Android Studio (SDK) Tools Design and implementation of a social networking site View project Mobile Quiz on Android Platform View project Apply Android Studio (SDK) Tools Design and implementation of a social networking site View project classification in data mining using weka View project Apply Android Studio (SDK) Tools (Vol. 5, Issue 5). https://www.researchgate.net/publication/331673953
[8] Chaniotis, I. K., Kyriakou, K. I. D., \& Tselikas, N. D. (2015). Is Node.js a viable option for building modern web applications? A performance evaluation study. Computing, 97(10), 1023-1044. https://doi.org/10.1007/s00607-014-0394-9.

[9] Ng, P. C., Spachos, P., \& Plataniotis, K. (2020). COVID-19 and Your Smartphone: BLE-based Smart Contact Tracing. http://arxiv.org/abs/2005.13754.

[10] Hatke, G. F., Montanari, M., Appadwedula, S., Wentz, M., Meklenburg, J., Ivers, L., Watson, J., \& Fiore, P. (n.d.). Using Bluetooth Low Energy (BLE) Signal Strength Estimation to Facilitate Contact Tracing for COVID-19. 